\title{
Sol-gel glasses: some recent trends
}

\author{
D GANGULI
}

Sol-Gel Laboratory, Central Glass and Ceramic Research Institute, Calcutta 700032, India

\begin{abstract}
The basic experimental steps in the preparation of sol-gel glass as developed in recent times, and their relevance have been discussed taking high purity silica glass as an example. Current developments in sol-gel derived ultra-low expansion glasses, rare earth doped laser glasses, semiconductor-doped non-linear glasses, gradient index lenses, microoptics and organic molecule-doped (mainly dyes) glasses for sensor and other applications have been discussed in brief.
\end{abstract}

Keywords. Sol-gel; silica glass; doped silica; silicate glasses.

\section{Introduction}

Production of glasses by the basic procedure of melting-cooling-annealing and its variants is a historically evolved industrial practice. While such procedures are convenient for producing most of the commercial glasses, some special glasses are indeed known to be less amenable to them. Some of the difficulties acknowledged by the classical glass melting technique are: (i) Requirement of high temperature facilities $\left(2000^{\circ} \mathrm{C}\right.$ or more) for glasses for special applications, e.g. pure silica, doped (e.g. rare earths) silica and titania-silica glasses, (ii) requirement of special refractories for the high-melting glasses, (iii) corrosion of refractories and the resulting contamination of glass in case of low viscosity melts and (iv) preferential vaporization of raw materials and consequent defects and shift from target composition.

For special glasses, therefore, alternative simpler routes have been looked for. While chemical vapour deposition has been proved to be a powerful technique specially for high melting glasses, sol-gel processing has also enjoyed wide attention because of its built-in versatility and simplicity, and specially, the relatively low temperature of operation.

The advantages of sol-gel processing have been discussed by many authors, and will not be elaborated here; it is sufficient to mention that all the difficulties for special glasses, as listed above, can be overcome by the sol-gel process. Homogeneity of multicomponent sol-gel glasses is, of course, a critical issue, and merits separate discussion.

The present paper will attempt to highlight some critical issues in sol-gel glass making, as also describe selectively and in brief some of the current trend-setting activities in the development and application of sol-gel glasses.

\section{Sol-gel glass .... glass?}

Since the virtual rejection of the ASTM definition of glass as an inorganic product of fusion, no clear-cut definition to everybody's satisfaction has come forward. The blanket definitions indicating glass to be an amorphous/non-crystalline/uncrystallized material (Secrist and Mackenzie 1964; Doremus 1973; Scholze 1991) have been objected to as being very general because, for example, such definitions would certify 
a piece of silica gel as silica glass (Scholze 1991)! The question if a 'glass' which has no melting history behind it would exhibit a $T_{\mathrm{g}}$ has been answered in the affirmative in case of some sol-gel glasses (Mackenzie 1982; Weinberg 1986) as examples. Wide acceptance of adequately dried (dehydroxylated) and densified gels as 'glass' has of course come through approximate matching of their ambient (e.g. refractive index, hardness, density) and some above-ambient (e.g. thermal expansion, high temperature viscosity) properties with those of the corresponding melt-derived dry and dense glasses. Some of these issues have been addressed by Weinberg (1986) and Brinker and Scherer (1990).

The journey of a bulk gel to a glass by thermal densification is accompanied by the following progressive changes which can be completed under the best of conditions (e.g. optimum gel structure, atmosphere of heating, maximum temperature, heating schedule): (i) Expulsion of volatiles including molecular water, (ii) elimination of $\mathrm{OH}$ and water generated by $\mathrm{OH}-\mathrm{OH}$ reaction, (iii) elimination of pores, specially micropores, (iv) substantial reduction of surface area and (v) reorientation of (and elimination of some of) the structural elements towards a stable, glass-like structural state.

At intermediate stages (e.g. thermal treatment well below $T_{\mathrm{g}}$ ), the above processes are only partially complete and the host of intermediate materials that can be produced in this way remain away from the targeted dry and dense products in all their properties. The sol-gel literature is replete with examples of such intermediate products, specially partially densified, hydroxyl-containing silica and silicate thin films baked at low temperatures $\left(400^{\circ}-500^{\circ} \mathrm{C}\right)$. The issue has been examined in some detail by Almeida and Pantano (1990). Such materials are loosely described as glass and the practice will probably continue until more rigid boundary conditions are defined for glass. For exactly duplicating a homogeneous and dense melt-glass, substantial elimination of $\mathrm{Si}-\mathrm{OH}$ non-bridging oxygens and near-complete to complete densification of a compositionally homogeneous starting gel seem to be the basic necessities. When such goals are achieved to a satisfactory level, the structural features also approach a stable, glasslike state in a cooperative fashion. Subtle but clear and progressive evolution of the structural features of a gel towards those of the corresponding melt-glass have been recorded via vibrational spectroscopy and comparison between the two made by X-ray diffraction by different workers (Bertoluzza et al 1982; Yoshino et al 1990; Kamiya et al 1992; De et al 1993a).

\section{Silica glass: a case in point}

The most intensive efforts in developing sol-gel processes for glassmaking have been put in recent times in the area of high purity silica glass. The reasons for this selection lie not only in the general necessity for developing a low temperature process, but also in the wide applicability of the material; optical communication is one important example where dense, low-hydroxyl and low-defect silica glass is required. Various sol-gel processes have been developed for silica glass (Matsuyama et al 1984; Rabinovich 1988; Shoup 1988; Clasen 1987, 1988; Toki et al 1988; Hench et al 1992; Kundu et al 1992; De et al 1993b), though some major features are common to all of them. This is briefly discussed below.

A dry xerogel ready for conversion to glass has a density somewhere in the approximate range $0.6-1.5 \mathrm{~g} / \mathrm{cm}^{3}$ (fully dense silica glass has a density of about $2 \cdot 2 \mathrm{~g} / \mathrm{cm}^{3}$ ) depending on the starting material and preparative procedure. The available 
pore surface at this stage is usually covered with hydroxyl groups. Further hydroxyl $(\mathrm{Si}-\mathrm{OH})$ is generated by decomposition of molecular water present in the pores during thermal treatment. Such hydroxyl groups react at elevated temperatures:

$$
\equiv \mathrm{Si}-\mathrm{OH}+\mathrm{HO}-\mathrm{Si} \equiv \rightarrow \equiv \mathrm{Si}-\mathrm{O}-\mathrm{Si} \equiv+\mathrm{H}_{2} \mathrm{O} \text {. }
$$

The escape of water vapour thus generated must be monitored and minimized to avoid cracking of the gel. Two routes are used: (i) vacuum treatment at an early stage of gel-glass conversion so as to decrease the content of molecular water at a later stage and (ii) $\mathrm{OH}-\mathrm{Cl}, \mathrm{OH}-\mathrm{F}$ or $\mathrm{Cl}-\mathrm{F}$ exchange by passing suitable gases during heating to minimize formation of $\mathrm{H}_{2} \mathrm{O}$ by $\mathrm{OH}-\mathrm{OH}$ reaction, e.g.

$$
2 \mathrm{Si}-\mathrm{OH}+2 \mathrm{Cl}_{2} \stackrel{800^{\circ} \mathrm{C}}{\longrightarrow} 2 \mathrm{Si}-\mathrm{Cl}+2 \mathrm{HCl}+\mathrm{O}_{2}
$$

Re-oxidation is often necessary for decreasing the chloride content, so that bubbling by chlorine evolved during use at high temperatures can be avoided. Chlorine, however, helps removal of metallic impurities via formation of volatile metal chlorides during glass preparation (MacChesney et al 1987a). Fluorine, on the other hand, decreases the refractive index of the glass (so-called 'down doping' in optical fibres) and helps avoidance of bubble formation at high temperature. Helium is used as the scavenging gas at the final stage of pore elimination. When all these steps are rigidly followed, an essentially hydroxyl-free or low-hydroxyl and pore-free glass is obtained.

The steps described above form the basic outline for silica gel-glass conversion, though gels may have been obtained from different starting materials, viz. silicon alkoxides (Matsuyama et al 1984; Hench et al 1992), fumed silica (Clasen 1988; Rabinovich 1988), a combination of the two (Toki et al 1988; Kundu et al 1992; De et al 1993b) and alkali silicates (Shoup 1988, 1991). It must be mentioned here that silica glasses prepared by the above routes are usable at high temperatures (softening for joining, melting for fibre drawing etc) in the same way as a melt-derived, defect-free glass without bloating or bubbling. They thus earn full credit for behaving like a 'normal' glass.

The sol-gel process for silica glass has been used in the last decade for the development of low-loss optical communication fibres. Two approaches have been pursued: development of all-gel-derived fibres, and fibres with gel-derived material as an optically passive part. Kitagawa et al (1987) obtained fibres from F-doped gel-glass tubes in which fluorine was removed from the internal surface. The fibres thus derived recorded a minimal loss of $0.43 \mathrm{~dB} / \mathrm{km}$. MacChesney et al (1987b) on the other hand used a hybrid system where an overclad of a thick gel tube was provided on commercial $\mathrm{GeO}_{2}$-doped core and $\mathrm{SiO}_{2}$ clad; the reported loss of the fibre was about $0.4 \mathrm{~dB} / \mathrm{km}$. An F-doped, gel-derived substrate tube was used by MacChesney et al (1985) to obtain fibres showing a minimal loss of $0 \cdot 28 \mathrm{~dB} / \mathrm{km}$.

Another area in which important developmental work has been carried out recently using sol-gel silica or silicate glass is micro-optics and optics with complicated shapes (Shoup 1991; Hench and Nogues 1994). Some items which have been developed using elegant processing techniques are (i) lightweight mirrors with integrally cast face plate and honeycomb backing, (ii) refractive micro-lens array, (iii) binary optics (micro-lens 
singlets and arrays) and (iv) sinusoidal diffraction gratings. Development of sol-gel silica micro-optics has made it necessary to cast a hard look at the shrinkage behaviour of gels obtained from sols of different characteristics (viscosity, surface tension etc) so as to optimize the designs of moulds with micron-level features for sol casting. This critical issue has been discussed by Hench and Nogues (1994). Other developmental techniques used in recent times include stamping (Tohge et al 1988) and laser densification (Taylor and Fabes 1992) of silica and silicate gel films before gel-glass conversion.

\section{Other glasses}

A large variety of two- to multicomponent oxide glasses have been synthesized via sol-gel processing. Surveys have been made by James (1988) and Rabinovich (1994) among others. Among these, two compositional areas can be selected as examples because of their potentiality in direct practical use. The current status in both the cases is discussed below with typical examples. Finally, brief mention will be made of dye-doped and semiconductor-doped glasses, and GRIN lenses as emerging materials.

\section{1 $\mathrm{TiO}_{2}-\mathrm{SiO}_{2}$ glasses}

Low-titania $(5-10 \mathrm{wt} \%$ ) silicate glasses are well-known for high melting temperature and ultra low thermal expansion (ULE). Various sol-gel techniques have been employed to prepare such glasses. In a recent work, Deng et al (1988) dispersed fumed silica in a titania sol to obtain a gel and densified the gel at $1500^{\circ} \mathrm{C}$ to convert it into a ULE glass. Abe et al (1988) used partially complexed titanium isopropoxide and tetrahydrofuran solution of silicic acid as starting materials to incorporate up to $50 \mathrm{wt} \% \mathrm{TiO}_{2}$ without crystallization at $1000^{\circ} \mathrm{C}$. Minehan et al (1989) used sol-gel derived colloids of $\mathrm{TiO}_{2}$ and $\mathrm{SiO}_{2}$ to obtain tape cast or pressed bodies which were converted to glass via sintering. In a very recent work, $6-7 \mathrm{wt} \% \mathrm{TiO}_{2}$ was incorporated in ULE sol-gel glass (typically +0.96 to $-0.61 \times 10^{-7} /{ }^{\circ} \mathrm{C}$ ) by using a new drying control chemical additive and a combination of Ti-isopropoxide and chloride (Aizawa et al 1994).

\subsection{Rare earth doped silica glasses}

The available combinations of high thermal shock resistance of silica glass and unique optical behaviour of some rare earth $(\mathrm{RE})$ ions in glass have prompted.several groups to develop RE doped silica glass for laser and filter applications. Most of such work involves incorporation of $\mathrm{Nd}^{3+}$ in alkoxide-derived silica glass (Pope and Mackenzie 1988; Mathur and Pye 1990; Moreshead et al 1990; Thomas et al 1992) but also other dopings (Patra and Ganguli 1993; Rabinovich et al 1993).

The basic difficulty of uniformly dispersing the RE ions proved to be a stumbling block in an otherwise easy process, but recent work (Thomas et al 1992) has provided a chemical solution with apparently high potential. Sol-gel laser glass rods produced in this way with homogeneous $\mathrm{Nd}$-doping and $\mathrm{Al}-\mathrm{Co}$-doping exhibited emission lifetimes greater than $400 \mu$ s and quantum yields greater than $50 \%$. 


\subsection{Dye-doped glasses, semiconductor-doped glasses and GRIN lenses}

Introduction of organic molecules and enzymes in gels and converting the gels to partially densified 'glasses' is currently a very active area of sol-gel research. Various optical and chemical sensors have been developed by doping of molecules in porous silica glass (Rottman et al 1992). Other areas relate to development of fluorescent and photochromic materials (Zink and Dunn 1991).

Sol-gel processing has also proved to be a very convenient way of doping quantum sized semiconductor (notably CdS) crystals in glass. Intensive efforts are currently going on for developing new optically non-linear materials by this route (Nogami et al $1990,1991)$. The sulphide nanocrystals are generated in situ or via $\mathrm{H}_{2} \mathrm{~S}$ treatment of monolithic silica or silicates.

Finally, the sol-gel technique is also being extensively used (Yamane 1990) for the development of radial graded index (r-GRIN) lenses. The basic technique commonly involves leaching of silicate $\left(\mathrm{TiO}_{2}-\mathrm{SiO}_{2}, \mathrm{GeO}_{2}-\mathrm{SiO}_{2}, \mathrm{PbO}-\mathrm{SiO}_{2}\right.$ etc) gel rods followed by their densification to glass, so as to obtain a progressive change in refractive index from the core to the margin.

The above account is but a condensed and truncated review of the global activity in sol-gel glassmaking, and only aims at indicating the major visible trends in this rapidly growing field.

\section{Acknowledgement}

Thanks are due to my colleagues at the Sol-Gel Laboratory for many useful discussions.

\section{References}

Abe Y, Sugimoto N, Nagao Y and Misono T 1988 J. Non-Cryst. Solids 104164

Aizawa M, Nosaka Y and Fujii N 1994 J. Non-Cryst. Solids 16849

Almeida R M and Pantano C G 1990 J. Appl. Phys. 684225

Bertoluzza A, Fagnano C, Morelli M A, Gottardi V and Guglielmi M 1982 J. Non-Cryst. Solids 48 117

Brinker C J and Scherer G W 1990 Sol-gel science: the physics and chemistry of sol-gel processing (Boston: Academic Press) pp. 760-777

Clasen R 1987 J. Non-Cryst. Solids 89335

Clasen R 1988 J. Mater. Sci. Lett. 7477

De G, Kundu D, Karmakar B and Ganguli D 1993a J. Non-Cryst. Solids 155253

De G, Kundu D, Karmakar B and Ganguli D 1993b Mater. Lett. 16231

Deng Z, Breval E and Pantano C G 1988 J. Non-Cryst. Solids 100364

Doremus R H 1973 Glass science (New York: Wiley) p. 1

Hench L L and Nogues J L 1994 in Sol-gel optics: processing and applications (ed.) L C Klein (Boston: Kluwer) p. 59

Hench L L, Wilson M J R, Balaban C and Nogues J L 1992 in Ultrastructure processing of advanced materials (eds) D R Uhlmann and D R Ulrich (New York: Wiley) p. 159

James P F 1988 J. Non-Cryst. Solids 10093

Kamiya K, Wada M, Matsuoka J and Nasu H 1992 in Structure and formation of glasses (ed.) S Sakka (Kyoto: Proc. Japan-Russia-China Seminar) p. 17

Kitagawa T, Shibata S and Horiguchi M 1987 Electron. Lett. 231295

Kundu D, De G, Karmakar B, Patra A and Ganguli D 1992 Bull. Mater. Sci. 15453 
MacChesney J B, Johnson D W Jr., Lemaire P J, Cohen L G and Rabinovich E M 1985 J. Lightwave Technol. LT-3 942

MacChesney J B, Johnson D W Jr., Fleming D A, Walz F W and Kometani T Y 1987a Mater. Res. Bull. 221209

MacChesney J B, Johnson D W, Fleming D A and Waltz F W 1987b Electron. Lett. 231005

Mackenzie J D 1982 J. Non-Cryst. Solids 481

Mathur A and Pye L D 1990 SPIE 2121327

Matsuyama I, Susa K, Satoh S and Suganuma T 1984 Bull. Am. Ceram. Soc. 631408

Minehan W T, Messing G L and Pantano C G 1989 J. Non-Cryst. Solids 108163

Moreshead W V, Nogues J-L R and Krabill R H 1990 J. Non-Cryst. Solids 121267

Nogami M, Nagasaka K and Kato E 1990 J. Am. Ceram. Soc. 732097

Nogami M, Zhu Y Q, Tohyama Y, Nagasaka K, Tokizaki T and Nakamura A 1991 J. Am. Ceram. Soc. 74238

Patra A and Ganguli D 1993 J. Mater. Sci. Lett. 12116

Pope E J A and Mackenzie J D 1988 J. Non-Cryst. Solids 106236

Rabinovich E M 1988 in Sol-gel technology for thin films, fibres, preforms, electronics and speciality shapes (ed.) L C Klein (New Jersey: Noyes Publications) p. 260

Rabinovich E M 1994 in Sol-gel optics: processing and applications (ed.) L C Klein (Boston: Kluwer) p. 1

Rabinovich E M, Bruce A J, Kopylov N A and Trevor P L 1993 J. Non-Cryst. Solids 160126

Rottman C, Ottolenghi M, Zusman R, Lev O, Smith M, Gong G, Kagan M L and Avnir D 1992 Mater. Lett. 13293

Secrist D R and Mackenzie J D 1964 in Modern aspects of the vitreous state (ed.) J D Mackenzie (London: Butterworths) vol. 3 p. 149

Scholze H 1991 Glass - nature, structure, properties (New York: Springer-Verlag) p. 3

Shoup R D 1988 in Ultrastructure processing of advanced ceramics (ed.) J D Mackenzie and D R Ulrich (New York: Wiley) p. 347

Shoup R D 1991 Bull. Am. Ceram. Soc. 701505

Taylor D J and Fabes B D 1992 J. Non-Cryst. Solids $147 \& 148457$

Thomas I M, Payne S A and Wilke G D 1992 J. Non-Cryst. Solids 151183

Tohge N, Matsuda A, Minami T, Matsuno Y, Katayama S and Ikeda Y 1988 J. Non-Cryst. Solids 100501

Toki M, Miyashita S, Takeuchi T, Kanbe S and Kochi A 1988 J. Non-Cryst. Solids 100479

Weinberg M C 1986 in Better ceramics through chemistry II (eds.) C J Brinker, D E Clark and D R Ulrich (Pittsburgh: Materials Research Society) p. 431

Yamane M 1990 SPIE 1328133

Yoshino H, Kamiya K and Nasu H 1990 J. Non-Cryst. Solids 12668

Zink J I and Dunn B J 1991 J. Ceram. Soc. Jap. 99878 